\title{
Green UHPLC Method for Simultaneous Determination of Febuxostat and Diclofenac in Pharmaceutical Dosage Form and Human Plasma
}

\author{
Shimaa A. Mahmoud ${ }^{*}$, Amira M. El-Kosasy², Fatma A. Fouad1 \\ ${ }^{1}$ Pharmaceutical Analytical Chemistry Department, Faculty of Pharmacy, Al-Azhar University, Cairo, Egypt \\ ${ }^{2}$ Pharmaceutical Analytical Chemistry Department, Faculty of Pharmacy, Ain Shams University, Cairo, Egypt \\ Email: ^Shimaa.ahmed22@azhar.edu.eg
}

How to cite this paper: Mahmoud, S.A., El-Kosasy, A.M. and Fouad, F.A. (2021) Green UHPLC Method for Simultaneous Determination of Febuxostat and Diclofenac in Pharmaceutical Dosage Form and Human Plasma. Journal of Analytical Sciences, Methods and Instrumentation, 11, 29-45. https://doi.org/10.4236/jasmi.2021.114004

Received: October 29, 2021

Accepted: December 17, 2021

Published: December 20, 2021

Copyright $\odot 2021$ by author(s) and Scientific Research Publishing Inc. This work is licensed under the Creative Commons Attribution International License (CC BY 4.0).

http://creativecommons.org/licenses/by/4.0/

\begin{abstract}
Eco-friendly Ultra-high-performance liquid chromatography (UHPLC) with green aqueous-organic mobile phase was applied for the simultaneous determination of febuxostat (FEB) and diclofenac (DIC) with the composition of water:ethanol $(85: 15 \mathrm{v} / \mathrm{v})$ utilizing phenomenex Kinetex $\mathrm{C}_{18}$ column $(4.6 \times$ $100 \mathrm{~mm} 2.6 \mu \mathrm{m}$ ), flow rate $1 \mathrm{ml} / \mathrm{min}$ and UV detection at $280 \mathrm{~nm}$ with linear ranges of $0.4-4.0 \mu \mathrm{g} / \mathrm{mL}$ and $0.5-5.0 \mu \mathrm{g} / \mathrm{mL}$ for FEB and DIC, respectively. The proposed method was also successfully applied to analyze the two drugs in pharmaceutical dosage form and human plasma. The results obtained were validated and statistically analyzed and found to be in accordance with those given by reported methods. Moreover, the greenness of the developed method is assessed using suitable analytical Eco-Scale and GAPI tools and comparison with the previously published methods have been carried out to indicate the priority of the proposed method. UHPLC is considered eco-friendly method regarding uses of safe solvents, simple, accurate and short time of analysis.
\end{abstract}

\section{Keywords}

Febuxostat, Diclofenac, Ultra-High-Performance Liquid Chromatography, Eco-Scale, Green Analytical Procedure Index Tools

\section{Introduction}

Febuxostat (FEB) is 2-[3-cyano-4-(2-methyl propoxy) phenyl]-4-methyl-1, 3 thiazole-5-carboxylic acid [1], Figure 1(a). It is a xanthine oxidase inhibitor that 
is used in the treatment of hyperuricemia and chronic gout [2]. It is a nonpurine selective inhibitor of xanthine oxidase. FEB was found to be superior to allopurinol in reducing the serum uric acid levels [3]. To decrease inflammation and control pain in gout attacks, some dosage forms containing a NSAID such as diclofenac potassium (DIC) are co-formulated. DIC is a potassium salt of 2-(2, 6-dichloranilino) phenyl acetic acid [1], Figure 1(b). The literature review revealed few analytical methods for simultaneous analysis of FEB and DIC. These methods include: spectrophotometry [4] [5] [6] [7], HPTLC methods [7] [8] and HPLC methods [9] [10]. FEB is not official in any pharmacopoeia while DIC is official in British, United States and European Pharmacopoeias [11] [12] [13]. All these methods have threats to the environment as they are using or applying hazardous solvents and chemicals, and the green analytical chemistry principles were not implemented.

In modern analytical chemistry, establishing a greener method implies bearing in mind the green aspects from the early stages of method development to ensure the reduction or elimination of hazardous substances that are either utilized in or produced by the method, thus, turning it to be a much safer method to the environment [14] [15]. Recently, UHPLC has been frequently proposed as an alternative to HPLC, which means introducing an environment-friendly approach to drug analysis achieved by reducing the consumption of solvents. It also offers greater chromatographic resolution and higher sensitivity as well as requiring less time due to faster analysis [16] [17]. As the development of a green analytical method is highly recommended, the presence of assessment tools to evaluate the greenness profile of the developed method is highly important as well. One of the assessment tools is the Analytical Eco-Scale [18] and recently a new tool known as the Green Analytical Procedure Index (GAPI) [19] was established to assess the green character of a whole analytical method. It is ideal to apply the two tools to obtain a deeper view on the greenness of a method. With virtually no development effort or investment required, LC methods utilizing fully porous column technology can easily be improved in resolution, sensitivity, and productivity by simply replacing the $5 \mu \mathrm{m}$ or $3 \mu \mathrm{m}$ fully porous columns with an equivalent Kinetex Core-Shell column. The Kinetex Core-Shell technology achieves higher chromatographic efficiencies in comparison to fully porous particles of similar diameters and under similar method conditions. This

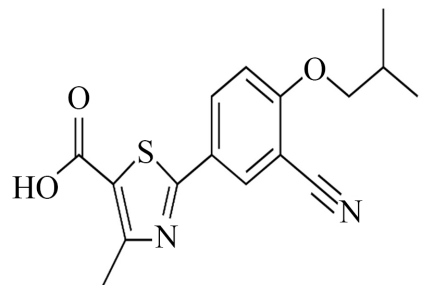

(a)

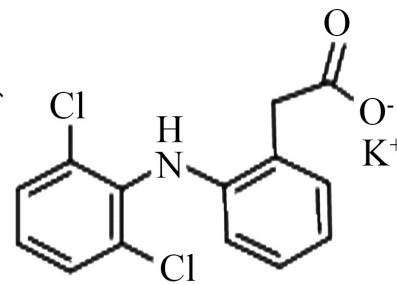

(b)

Figure 1. Chemical structures of (a) Febuxostat and (b) Diclofenac potassium. 
efficiency gain allows chromatographers to maximize the performance out of their HPLC/UHPLC system by using the right particle morphology for the application. The proposed method included development for the first time of simple, rapid and green UHPLC method using Kinetex $\mathrm{C}_{18}$ column with UV detection for the quantitative determination of the two cited drugs in their pharmaceutical dosage form and human plasma with accepted accuracy and precision, this is allow using it in routine analysis laboratories.

\section{Experimental}

\subsection{Instrumental}

- Phenomenex Kinetex $\mathrm{C}_{18}$ column $(4.6 \times 100 \mathrm{~mm} 2.6 \mu \mathrm{m})$ with binary pump and UV detector (USA).

- Vortex mixer (Model: VM-300P, Gemmy Industrial Corp., Taiwan) was used for human plasma samples preparation

- Centrifuge (Model: 2-16P, Sigma Laborzentrifugen, Germany) was used for human plasma samples preparation.

- Sonicator (Thermo Scientific, Waltham, USA).

\subsection{Chemicals and Reagents}

- Pure Febuxostat: B. No. OP-FAB/06/16/001 was kindly provided by Mash Premiere with purity $100.61 \%$ according to supplier.

- Pure diclofenac potassium: B. No. DK/1808/0080B was kindly provided by The Arab Company for Gelatin \& Pharmaceutical products with purity $99.85 \%$ according to supplier.

- Ethanol and methanol (Sigma - Aldrich, USA) analytical grade.

\subsection{Pharmaceutical Formulation}

- Xanfeb DSR ${ }^{\circledR}$ tablets, it is labelled to contain $40 \mathrm{mg}$ FEB and $100 \mathrm{mg}$ DIC manufactured by Indoco Remedies, India) were purchased from pharmacies.

\subsection{Standard Solutions}

Stock standard solutions of the drug $(1.0 \mathrm{mg} / \mathrm{mL})$ were prepared in methanol. Working solution $(0.1 \mathrm{mg} / \mathrm{mL})$ was prepared by dilution with the mobile phase.

\section{Procedures}

\subsection{Chromatographic Conditions}

- Mobile phase: consisted of water: ethanol (85:15 v/v) The mobile phase was filtered through $0.45-\mu \mathrm{m}$ Millipore membrane filter and degassed by sonication for $30 \mathrm{~min}$ before use

- flow rate: $1 \mathrm{ml} / \mathrm{min}$

- Detection: UV at $280 \mathrm{~nm}$

- Temperature: ambient temperature 


\subsection{Construction of the Calibration Graphs}

Accurately measured aliquots of the working standard solutions $(100 \mu \mathrm{g} / \mathrm{mL})$ were transferred into two separate sets of $10-\mathrm{mL}$ volumetric flasks and adjusted to volume with the mobile phase to obtain final concentrations of $(0.4-4.0$ $\mu \mathrm{g} / \mathrm{mL})$ or $(0.5-5.0 \mu \mathrm{g} / \mathrm{mL})$, respectively for FEB and DIC. The standard solutions were then analyzed by injecting $10 \mu \mathrm{L}$ of each solution under the above chromatographic conditions. The calibration graphs were constructed by plotting the peak area against the corresponding drugs concentration in $\mu \mathrm{g} / \mathrm{mL}$ and the corresponding regression equations were computed.

\subsection{Laboratory Prepared Mixtures}

Mixtures of different ratios for FEB and DIC were prepared by transferring aliquots from the corresponding working solutions $(100 \mu \mathrm{g} / \mathrm{mL})$, mixed well and completed to volume with mobile phase to be analyzed by the proposed method.

\subsection{Pharmaceutical Dosage Forms}

Ten tablets of Xanfeb DSR ${ }^{\circledR}$ were accurately weighed and grounded. An amount of the powder equivalent to $80 \mathrm{mg}$ FEB and $200 \mathrm{mg}$ DIC was transferred to a $50-\mathrm{mL}$ volumetric flask. A volume of $25 \mathrm{~mL}$ of methanol was added, and the flask was sonicated for $30 \mathrm{~min}$, then completed to volume with methanol followed by filtration. One milliliter of this solution was diluted to $100 \mathrm{~mL}$ with methanol to get the final solution of $16 \mu \mathrm{g} / \mathrm{mL}$ of FEB and $40 \mu \mathrm{g} / \mathrm{mL}$ of DIC and filtered through a $0.45-\mu \mathrm{m}$ membrane filter. Further dilution with the mobile phase was done to obtain the working standard solution to be analyzed as described above. The recovered concentration of each analyte was calculated from the corresponding regression equation.

\subsection{Preparation of Plasma Samples}

The calibration graphs were constructed using spiked human plasma as follows: in a stoppered centrifuge tube, an aliquot quantity of $300 \mu \mathrm{L}$ plasma was added and spiked with $100 \mu \mathrm{L}$ of working solutions of $(1.25,2.5,3.75,5$ and $7.5 \mu \mathrm{g} / \mathrm{mL})$ for FEB or $(2,5,7.5,10$ and $12.5 \mu \mathrm{g} / \mathrm{mL})$ DIC, $600 \mu \mathrm{L}$ methanol was added and the samples were vortex mixed for 5 minutes and centrifugated at $3000 \mathrm{rpm}$ for 15 minutes. $400 \mu \mathrm{L}$ of the supernatant was diluted with $600 \mu \mathrm{L}$ mobile phase to obtain final concentration in the range $0.05-0.3 \mu \mathrm{g} / \mathrm{mL}$ and $0.08-0.5 \mu \mathrm{g} / \mathrm{mL}$ for FEB and DIC; respectively, all samples were filtered through a $0.45-\mu \mathrm{m}$ membrane filter and directly injected into the chromatographic system under the above described conditions. The linear regression equations relating the peak areas to the concentration were derived for each analyte. A blank plasma experiment was performed simultaneously.

\section{Results \& Discussions}

The main green analytical chemistry principle utilized during the development 
of the proposed method was the elimination of hazardous solvents and their replacement with green ones. Therefore, ethanol was used in the mobile phase instead of acetonitrile or methanol which is the most commonly utilized solvents. According to the US Environmental Protection Agency (EPA), acetonitrile is ranked as hazardous solvent owing to its intrinsic toxicity [20]. However, based on environment, health and safety properties (EHS) and life cycle assessment (LCA); ethanol is considered a green solvent retaining a low impact on EHS [21] owing to its derivation from renewable sources, its minor toxicity and its ease of disposal [22]. Thus, a mobile phase composed of ethanol and water was developed. Regarding the stationary phase using phenomenex kinetex $\mathrm{C}_{18}$ column (4.6 $\times 100 \mathrm{~mm}, 2.6 \mu \mathrm{m}$ particle size) in our proposed method enabled significant reduction in retention time and solvent consumption than Agilent Zorbax SB- $\mathrm{C}_{18}$ column $(4.6 \times 250 \mathrm{~mm}, 5-\mu \mathrm{m}$ particle size $)$ attached to Agilent $\mathrm{C}_{18}(4.6 \times 12.5$ $\mathrm{mm}, 5-\mu \mathrm{m}$ particle size) guard column which was reported by F.A .El-Yazbi et al. [9]. Also phenomenex kinetex $\mathrm{C}_{18}$ column $(4.6 \times 100 \mathrm{~mm}, 2.6 \mu \mathrm{m}$ particle size $)$ which was used in our proposed method gave better sensitivity than phenomex $\mathrm{C}_{18}$ column $(4.6 \times 250 \mathrm{~mm}, 5-\mu \mathrm{m}$ particle size $)$ which was reported by $\mathrm{S}$. Vaibhav et al. [10]. Also the proposed UHPLC method was validated for the determination of FEB and DIC in their pharmaceutical dosage form and biological fluid. Moreover the greenness of the developed method is assessed using suitable analytical Eco-Scale and GAPI tools and comparison with the previously published methods has been carried out to indicate priority of the proposed method.

\subsection{Optimization of the Chromatographic Performance and System Suitability}

\subsubsection{System Suitability Testing}

System suitability test (SST) parameters were performed during the development and optimization of the method to ensure that the system is working correctly during the analysis. The test was performed by injecting the standard drug solution in triplicate and the parameters were calculated according to the BP [11] and USP [13] Guidelines. The final SST parameters including tailing factor (T), column efficiency (number of theoretical plates $N$ ) and Resolution (Rs) are summarized in Table 1.

\subsubsection{Detection Wavelength}

The UV absorption spectra of the methanolic solution of the studied drugs exhibited maxima at 316 for FEB and $283 \mathrm{~nm}$ for DIC as shown in Figure 2. Both drugs showed reasonable absorbance at about $280 \mathrm{~nm}$. However, three wavelengths $(230,254,280)$ were tried to select the most suitable one where $280 \mathrm{~nm}$ showed the highest sensitivity.

\subsubsection{Column}

Three different columns were used for performance investigations, including phenomenex kinetex $\mathrm{C}_{18}$ column (4.6- $\mathrm{mm} \times 100-\mathrm{mm}, 2.6 \mu \mathrm{m}$ particle size), $\mathrm{BDS}$ hypersil $\mathrm{C}_{18}$ column $(150 \mathrm{~mm} \times 4.6 \mathrm{~mm}, 5 \mu \mathrm{m}$ particle size $)$ and Intersil $\mathrm{C}_{18}$ 
(4.6-mm $\times 250-\mathrm{mm}, 5 \mu \mathrm{m}$ particle size). Experimental studies revealed that, the first column showed better results where the peaks of both analytes were more symmetrical and well-defined with a total run time less than 5 min. The second column was not suitable as it couldn't separate the two drugs. In addition, the third column resulted in asymmetrical peaks with delayed retention time (Table 1).

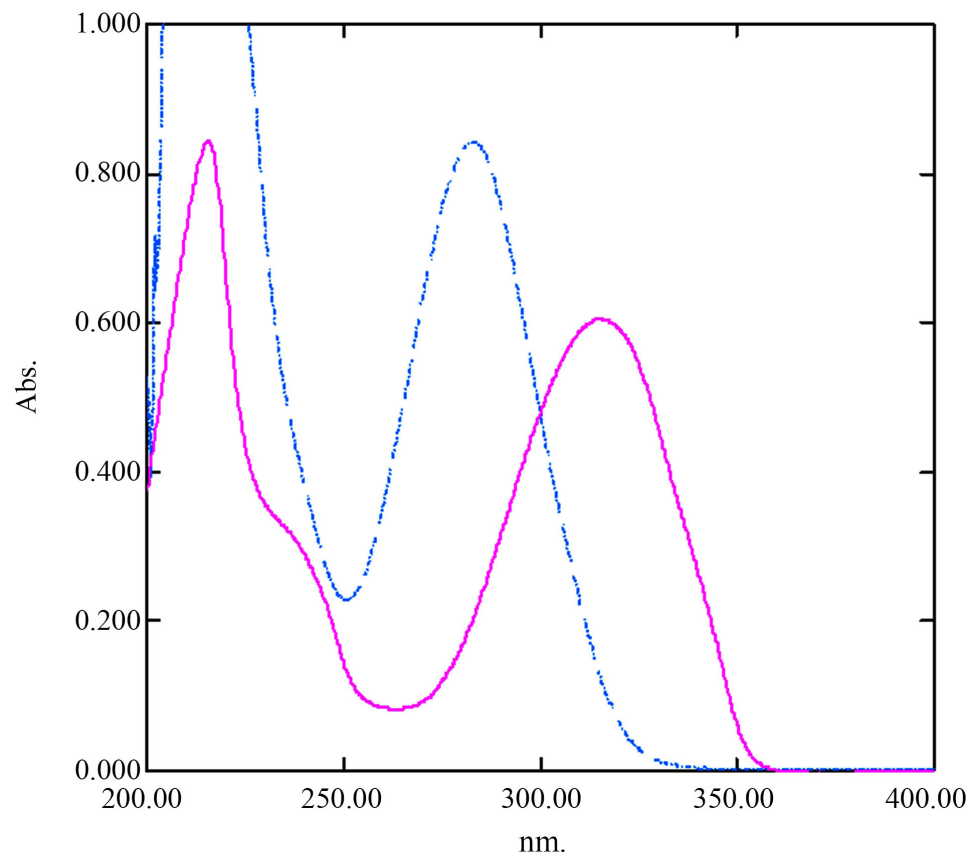

Figure 2. Zero order spectra of $(8 \mu \mathrm{g} / \mathrm{mL})$ of each FEB (red) \& $(20 \mu \mathrm{g} / \mathrm{mL})$ DIC (blue) in methanol.

Table 1. Optimization of the chromatographic conditions for determination of FEB and DIC by the proposed UHPLC method.

\begin{tabular}{|c|c|c|c|c|c|c|}
\hline & \multirow{2}{*}{ Parameter } & \multicolumn{2}{|c|}{ No. of theoretical plates } & \multirow[t]{2}{*}{ Resolution } & \multicolumn{2}{|c|}{ Tailing factor } \\
\hline & & FEB & DIC & & FEB & DIC \\
\hline \multirow{3}{*}{ Column } & Intersil $\mathrm{C}_{18}$ & - & 4244 & - & - & 1.18 \\
\hline & BDS hypersil $\mathrm{C}_{18}$ column & 3608 & 3916 & 3.41 & 1.32 & 1.22 \\
\hline & phenomenex kinetex $\mathrm{C}_{18}$ column & 4558 & 4787 & 5.18 & 1.09 & 1.11 \\
\hline \multirow{3}{*}{ Mobile phase } & ACN-buffer & 4215 & 3112 & 5.99 & 1.24 & 1.73 \\
\hline & Ethanol-water & 4558 & 4787 & 5.18 & 1.09 & 1.11 \\
\hline & Methanol-buffer & 4459 & --- & --- & 1.16 & --- \\
\hline \multirow{5}{*}{$\begin{array}{c}\text { Ethanol } \\
\text { concentration }(\% \mathrm{v} / \mathrm{v})\end{array}$} & $5 \%$ & 485 & 572 & 4.61 & 2.05 & 1.97 \\
\hline & $10 \%$ & 2300 & 1556 & 4.12 & 1.27 & 1.23 \\
\hline & $15 \%$ & 4558 & 4787 & 5.18 & 1.09 & 1.11 \\
\hline & $25 \%$ & 2859 & 3646 & 3.83 & 1.85 & 1.53 \\
\hline & $30 \%$ & 3152 & 2957 & 3.29 & 2.04 & 1.81 \\
\hline \multirow{4}{*}{$\begin{array}{l}\text { Flow rate } \\
(\mathrm{mL} / \mathrm{min})\end{array}$} & 0.6 & 2277 & 2804 & 3.91 & 1.38 & 1.26 \\
\hline & 0.8 & 3887 & 3915 & 5.26 & 1.26 & 1.14 \\
\hline & 1.0 & 4558 & 4787 & 5.18 & 1.09 & 1.11 \\
\hline & 1.2 & 2486 & 2961 & 4.83 & 1.18 & 1.16 \\
\hline
\end{tabular}




\subsubsection{Mobile Phase Composition}

Different mobile phases were tried as methanol: phosphate buffer, acetonitrile: phosphate buffer and ethanol:water. Initial experiments showed good separation with ethanol: water compared with the other mobile phases. Several modifications in the mobile phase composition were performed in order to study the possibilities of improving the performance of the chromatographic system which provide satisfactory, selectivity and sensitivity in a short separation time. Different $\%$ of ethanol were studied $(5 \%-30 \%)$ where $15.0 \%$ ethanol was found to be the optimum concentration regarding separation efficiency and resolution (Table 1).

\subsubsection{Flow Rate}

(Table 1) shows the effect of different flow rates $(0.6-1.2 \mathrm{~mL} / \mathrm{min})$ on the chromatographic separation. A flow rate was optimized at $1 \mathrm{~mL} / \mathrm{min}$ due to the highest efficiency in a short analysis time. Although lower flow rates showed higher resolution, but they were not selected as they led to an increase in the total run time, in addition to a decrease in the number of theoretical plates for both analytes. Optimum chromatographic conditions for the UHPLC determination of the studied drugs are summarized in Table 1. The proposed method permitted the separation of the two drugs with good resolution in a reasonable time, less than 5.0 min. Figure 3 shows typical chromatograms for laboratory prepared mixtures of FEB and DIC under the described chromatographic conditions where well-separated symmetrical peaks were observed. The retention times for FEB and DIC were 2.5 and $4.2 \mathrm{~min}$, respectively.

\section{Method Validation}

Validation of the developed UHPLC method was performed according to the international conference on harmonization (ICH) guidelines [23].

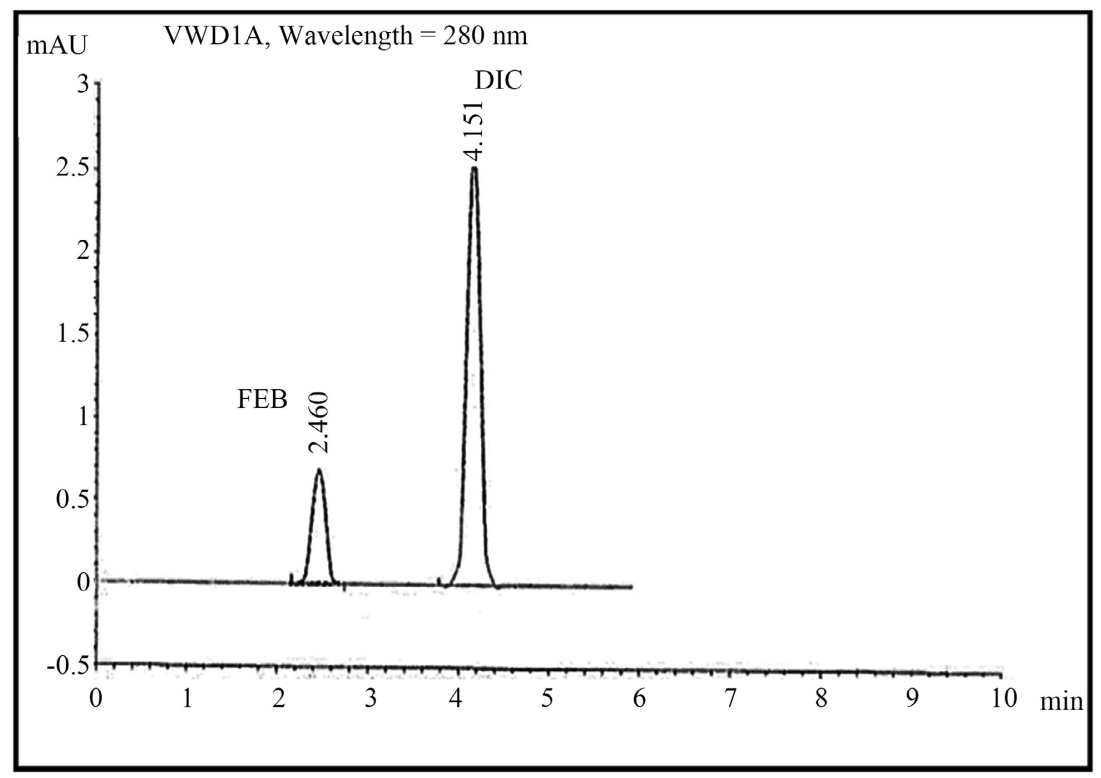

Figure 3. UHPLC chromatogram lab prepared mixture of febuxostat $(0.8 \mu \mathrm{g} / \mathrm{mL})$ and diclofenac potassium $(2.0 \mu \mathrm{g} / \mathrm{mL})(2: 5 \mathrm{ratio})$ at $280 \mathrm{~nm}$. 


\subsection{Linearity and Range}

The linearity of the developed method was confirmed by plotting the peak area against the analyte concentration in $\mu \mathrm{g} / \mathrm{mL}$. The graphs were linear over the concentration range of $(0.4-4.0 \mu \mathrm{g} / \mathrm{mL})$ and $(0.5-5.0 \mu \mathrm{g} / \mathrm{mL})$ for FEB and DIC; respectively. Linear regression analysis of the obtained data was presented in Table 2.

\subsection{Limits of Detection and Quantitation}

LODs were determined by evaluating the lowest concentration of the analytes which could be detected but not necessarily quantitated as exact values. LOQs were determined by establishing the lowest concentration of the analytes which could be quantitatively measured with suitable precision and accuracy. The results are shown in Table 2.

\subsection{Accuracy}

The accuracy of the results was checked by applying the proposed method for determination of different samples of FEB and DIC. The concentrations were obtained from the corresponding regression equations of the calibration graphs. The $\%$ recoveries for the proposed method were $99.76 \%$ and $100.63 \%$ for FEB and DIC as shown in Table 2.

\subsection{Precision}

Three different concentrations $(0.8,2.4$ and $3.6 \mu \mathrm{g} / \mathrm{mL})$ of FEB and $(1,3$ and 4.5 $\mu \mathrm{g} / \mathrm{mL}$ ) of DIC solution were analyzed three times each, intra-daily and on three successive days using the previous mentioned procedure described for linearity. The relative standard deviations for the two drugs were calculated using the corresponding regression equations. The results are shown in Table 2.

Table 2. The regression parameters and validation results for determination of FEB and DIC by the proposed method.

\begin{tabular}{ccc}
\hline Parameter & \multicolumn{2}{c}{ Results } \\
\cline { 2 - 3 } & FEB & DIC \\
\hline Wave length $(\mathrm{nm})$ & 280 & 280 \\
Linearity range $\mu \mathrm{g} / \mathrm{mL}$ & $0.4-4$ & $0.5-5$ \\
Slope & 6.5171 & 8.3367 \\
Intercept & -0.0087 & -0.0145 \\
Determination coefficient $\left(\mathrm{r}^{2}\right)$ & 0.9999 & 0.9998 \\
Accuracy $(\% \mathrm{R})$ & 99.76 & 100.63 \\
Inter-day precision RSD\% & 0.336 & 1.187 \\
Intra-day precision RSD\% & 0.0651 & 1.017 \\
LOD $\mu \mathrm{g} / \mathrm{mL}$ & 0.0159 & 0.0263 \\
LOQ $\mu \mathrm{g} / \mathrm{mL}$ & 0.0481 & 0.0796 \\
\hline
\end{tabular}




\subsection{Robustness}

The robustness of the proposed method was indicated by the constancy of the peak area with deliberate changes in the experimental parameters. These parameters included ethanol concentration $(15 \% \pm 0.5 \%, \mathrm{v} / \mathrm{v})$ and UV detection $(280$ $\pm 1 \mathrm{~nm}$ ). These minor changes did not affect the peak area of both drugs confirming robustness of the method (Table 3).

\subsection{Selectivity}

The selectivity of the proposed method was assured by applying it to laboratory prepared mixtures of FEB and DIC at different concentrations within the linearity range. Good recoveries of both drugs were obtained as shown in Table 4.

\subsection{Sample Solution Stability and Mobile Phase Stability}

Evaluation of the stability of FEB and DIC standard solutions was achieved by quantification of each drug in this solution and comparing the results obtained to that obtained from freshly prepared standard solution. Similarly, the stability of the mobile phase was checked. No significant changes were observed in standard solution or mobile phase responses, relative to freshly prepared ones. The results obtained in both cases proved that the sample solution stable up to 7 days and mobile phase used during the assay were stable up to 5 days in refrigerator.

Table 3. Robustness of the proposed UHPLC method using FEB $(2.0 \mu \mathrm{g} / \mathrm{mL})$ and DIC $(3.0 \mu \mathrm{g} / \mathrm{mL})$.

\begin{tabular}{|c|c|c|c|c|}
\hline \multirow{2}{*}{ Parameter } & \multicolumn{2}{|c|}{ Conc. found ( $\mu \mathrm{g} / \mathrm{mL})$} & \multicolumn{2}{|c|}{$\%$ Found } \\
\hline & FEB & DIC & FEB & DIC \\
\hline \multicolumn{5}{|c|}{ Ethanol \% concentration $(v / v)$} \\
\hline 14.5 & 2.016 & 3.022 & 100.80 & 100.73 \\
\hline 15 & 1.994 & 2.997 & 99.70 & 99.90 \\
\hline 15.5 & 1.976 & 2.994 & 98.8 & 99.80 \\
\hline Mean\% & & & $99.77 \%$ & $100.14 \%$ \\
\hline$\pm \mathrm{SD}$ & & & 1.002 & 0.511 \\
\hline$\%$ RSD & & & 1.004 & 0.510 \\
\hline \multicolumn{5}{|c|}{ UV detection (nm) } \\
\hline 279 & 1.985 & 2.989 & 99.25 & 99.63 \\
\hline 280 & 1.996 & 3.014 & 99.80 & 100.47 \\
\hline 281 & 2.016 & 3.017 & 100.80 & 100.57 \\
\hline Mean\% & & & $99.95 \%$ & $100.22 \%$ \\
\hline$\pm \mathrm{SD}$ & & & 0.642 & 0.516 \\
\hline$\%$ RSD & & & 0.642 & 0.515 \\
\hline
\end{tabular}


Table 4. Determination of FEB and DIC in laboratory prepared mixtures by the proposed UHPLC method.

\begin{tabular}{|c|c|c|c|c|}
\hline \multicolumn{2}{|c|}{ Lab prepared mixture $\mu \mathrm{g} / \mathrm{mL}$} & \multirow{2}{*}{$\begin{array}{c}\text { FEB/DIC } \\
\text { ratio }\end{array}$} & \multicolumn{2}{|c|}{$\%$ Recovery } \\
\hline FEB & DIC & & FEB & DIC \\
\hline 0.8 & 2 & $2: 5^{*}$ & 98.63 & 101.55 \\
\hline 2 & 4 & $1: 2$ & 99.20 & 100.33 \\
\hline 4 & 2 & $2: 1$ & 99.73 & 100.25 \\
\hline 2 & 2 & $1: 1$ & 100.35 & 99.15 \\
\hline 1.2 & 3 & $2: 5^{*}$ & 100.42 & 99.87 \\
\hline \multicolumn{2}{|c|}{ Mean $\% \pm$ SD } & & $99.67 \% \pm 0.763$ & $100.23 \% \pm 0.873$ \\
\hline
\end{tabular}

${ }^{\star}$ Ratio of dosage form.

\subsection{Application of the Proposed Method for Determination of FEB and DIC in Their Laboratory Prepared Mixtures}

The proposed method was successfully applied to the simultaneous determination of FEB and DIC in laboratory prepared mixtures in different ratio and in their medicinally recommended ratios of 2:5; respectively as shown in Figure 3 and Table 4.

\subsection{Application of the Proposed Method to the Determination of the Studied Drugs in Their Pharmaceutical Dosage Form}

The proposed procedure was applied for the determination of FEB and DIC in their tablets. The obtained results were in good agreement with the label claim, indicating no interference from excipients and additives. The validity of the proposed method was further assessed by applying the standard addition technique, mean percentage recoveries of pure added were $100.28 \% \pm 1.099$ and 99.98\% \pm 1.871 for FEB and DIC; respectively (Table 5).

The obtained results were statistically compared to those obtained by the reported method [10]. No significant differences were found by applying t-test and F-test at $95 \%$ confidence level [24] indicating good accuracy and precision of the proposed method for the analysis of the studied drugs in its pharmaceutical dosage form as shown in Table 6 .

\subsection{Application of the Proposed Method for Determination of FEB and DIC in Spiked Human Plasma}

FEB is reported to be rapidly absorbed after single or repeated doses with a maximum plasma concentration $\left(C_{\max }\right)$ of $1.9 \pm 0.678 \mu \mathrm{g} / \mathrm{mL}$ reported for a 40 $\mathrm{mg}$ dose at $t_{\max } 1.0-1.5 \mathrm{~h} \mathrm{[25].} \mathrm{On} \mathrm{the} \mathrm{other} \mathrm{hand,} \mathrm{DIC} \mathrm{is} \mathrm{completely} \mathrm{absorbed}$ after oral administration. It exhibits a mean peak plasma concentration $\left(C_{\max }\right)$ $1.0 \mu \mathrm{g} / \mathrm{ml}$ after about two hours [26]. It is clear that UHPLC allows biological samples to be analyzed FEB and DIC a linear relationship was established by plotting the peak area against the drug concentration in $\mu \mathrm{g} / \mathrm{mL}$. Linear regression analysis of the data gave the following equation: 


$$
\begin{aligned}
& P=6.665 C-0.2266(r=0.9995) \text { for FEB } \\
& P=5.6548 C+0.1135(r=0.9993) \text { for DIC }
\end{aligned}
$$

Table 5. Determination of FEB and DIC in pharmaceutical dosage forms by the proposed UHPLC method and results obtained by

\begin{tabular}{|c|c|c|c|c|c|}
\hline \multicolumn{6}{|c|}{ Xanfeb DSR ${ }^{\circledR}$ contain $40 \mathrm{mg}$ febuxostat and $100 \mathrm{mg}$ diclofenac } \\
\hline & Claimed taken $(\mu \mathrm{g} / \mathrm{ml})$ & Pure added $(\mu \mathrm{g} / \mathrm{mL})$ & Mean $\% \pm$ SD & Pure found $(\mu \mathrm{g} / \mathrm{mL})$ & $\mathrm{R} \%$ of pure added \\
\hline & 0.8 & 1.6 & & 1.586 & 99.13 \\
\hline \multirow[t]{4}{*}{ FEB } & 0.8 & 2.4 & $100.28 \pm 1.185$ & 2.409 & 100.38 \\
\hline & 0.8 & 2.8 & & 2.837 & 101.32 \\
\hline & Mean $\% \pm S D$ & & & $100.28 \% \pm 1.09$ & \\
\hline & 2 & 1 & & 1.021 & 102.10 \\
\hline \multirow[t]{3}{*}{ DIC } & 2 & 2 & $99.92 \pm 1.036$ & 1.971 & 98.55 \\
\hline & 2 & 3 & & 2.979 & 99.30 \\
\hline & Mean $\% \pm$ SD & & & $99.98 \% \pm 1.87$ & \\
\hline
\end{tabular}
standard addition technique.

*average of five concentrations.

Table 6. Statistical comparison for the results obtained by the proposed UHPLC method and the reported method (10) for the

\begin{tabular}{|c|c|c|c|c|c|c|}
\hline & \multicolumn{3}{|c|}{ UHPLC method } & \multicolumn{3}{|c|}{ Reported method ${ }^{[10]}$} \\
\hline & Taken $\left(\mu \mathrm{g} \cdot \mathrm{mL}^{-1}\right)$ & Found* $(\mu \mathrm{g} / \mathrm{mL})$ & \% Recovery & Taken $(\mu \mathrm{g} / \mathrm{mL})$ & Found * $(\mu \mathrm{g} / \mathrm{mL})$ & \% Recovery \\
\hline & 0.4 & 0.395 & 98.75 & 5 & 5.06 & 101.19 \\
\hline \multirow[t]{4}{*}{ FEB } & 0.8 & 0.813 & 101.63 & 10 & 10.136 & 101.36 \\
\hline & 1.2 & 1.194 & 99.5 & 15 & 14.822 & 98.81 \\
\hline & 1.6 & 1.605 & 100.31 & 20 & 19.812 & 99.06 \\
\hline & 2 & 2.024 & 101.2 & 25 & 25.273 & 101.09 \\
\hline Mean $\% \pm S D$ & \multicolumn{3}{|c|}{$100.28 \% \pm 1.185$} & \multicolumn{3}{|c|}{$100.30 \% \pm 1.255$} \\
\hline t-test & \multicolumn{3}{|c|}{$0.031(2.306)$} & \multicolumn{3}{|c|}{-} \\
\hline F-test & \multicolumn{3}{|c|}{$1.121(6.388)$} & \multicolumn{3}{|c|}{-} \\
\hline \multirow{5}{*}{ DIC } & 1 & 1.006 & 100.6 & 20 & 19.99 & 99.95 \\
\hline & 2 & 1.988 & 99.4 & 30 & 29.817 & 99.39 \\
\hline & 3 & 3.041 & 101.37 & 40 & 40.268 & 100.67 \\
\hline & 4 & 3.975 & 99.38 & 50 & 50.105 & 100.21 \\
\hline & 5 & 4.942 & 98.84 & 60 & 59.898 & 99.83 \\
\hline Mean $\% \pm S D$ & \multicolumn{3}{|c|}{$99.92 \% \pm 1.036$} & \multicolumn{3}{|c|}{$100.01 \% \pm 0.473$} \\
\hline t-test & \multicolumn{3}{|c|}{$0.181(2.306)$} & \multicolumn{3}{|c|}{-} \\
\hline F-test & \multicolumn{3}{|c|}{$4.792(6.388)$} & \multicolumn{3}{|c|}{-} \\
\hline
\end{tabular}
analysis of FEB and DIC.

${ }^{\star}$ Average of three separate determinations. The values between parentheses are the tabulated $\mathrm{t}$ and $\mathrm{F}$ values at $P=0.05\left({ }^{24}\right)$. 
where: $P$ is the peak area, $C$ is the concentration of the drug in $\mu \mathrm{g} / \mathrm{mL}$ and $r$ is the correlation coefficient. The high value of the correlation coefficient $(r)$ indicated the good linearity of the calibration graph constructed in human plasma. The proposed method showed satisfying results for the determination of FEB and DIC in spiked human plasma over the concentration range of $0.05-0.3$ $\mu \mathrm{g} / \mathrm{mL}$ and $0.08-0.5 \mu \mathrm{g} / \mathrm{mL}$ for FEB and DIC; respectively, with a lower detection limit of $0.0106 \mu \mathrm{g} / \mathrm{mL}$ and $0.0231 \mu \mathrm{g} / \mathrm{mL}$ for FEB and DIC; respectively. The assay results using the proposed method are summarized in Table 7. Figure 4(a) and Figure 4(b) show representative chromatograms for blank and spiked plasma samples.

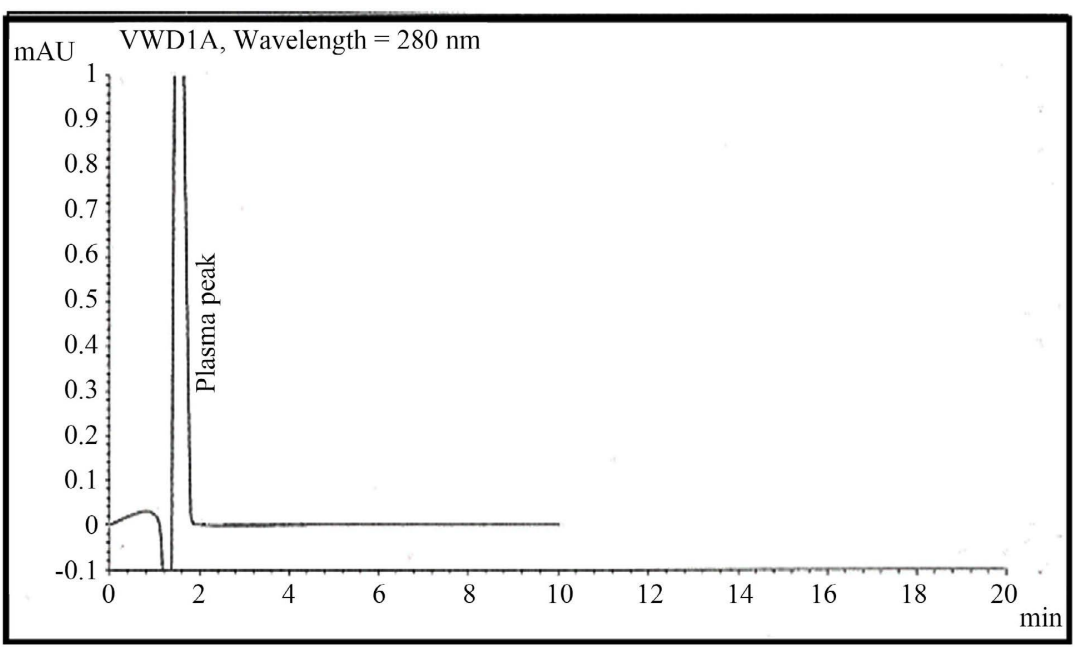

(a)

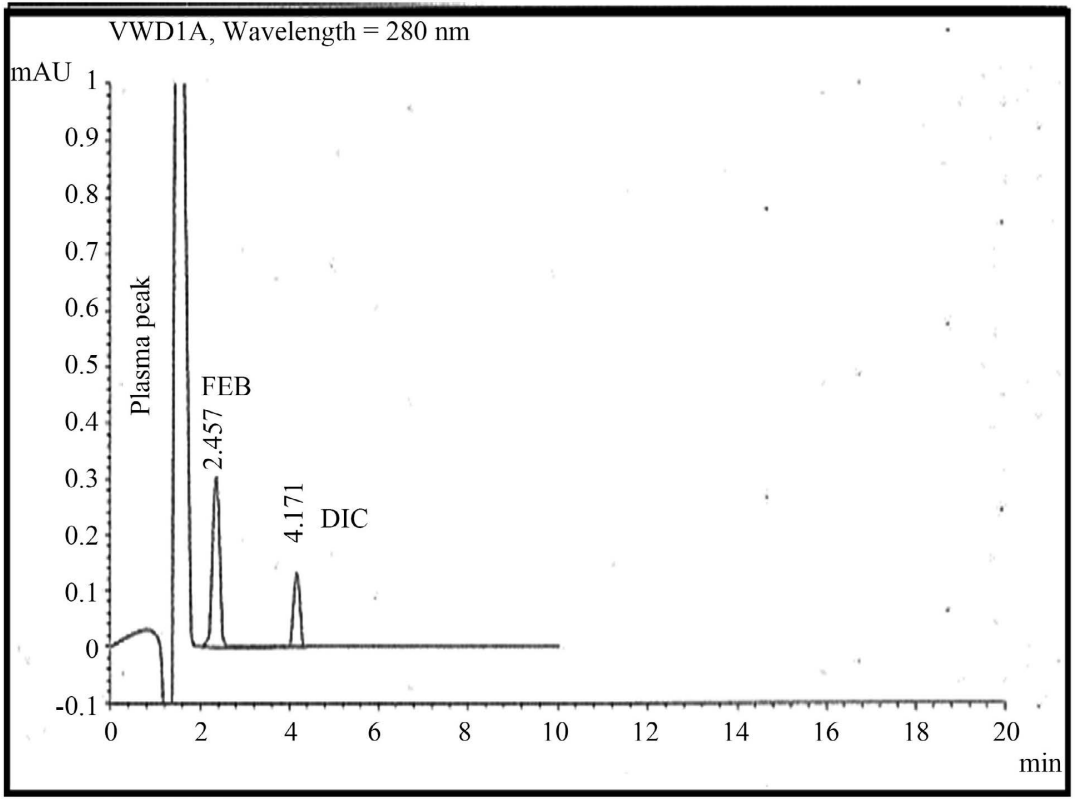

(b)

Figure 4. UHPLC chromatogram of blank plasma at $280 \mathrm{~nm}$ (a), UHPLC chromatogram of febuxostat $(0.3 \mu \mathrm{g} / \mathrm{mL})$ and diclofenac potassium $(0.08 \mu \mathrm{g} / \mathrm{mL})$ in spiked human plasma at $280 \mathrm{~nm}(\mathrm{~b})$. 
Table 7. Assay results for the determination of FEB and DIC in spiked human plasma by the proposed UHPLC method.

\begin{tabular}{|c|c|c|c|c|c|c|c|}
\hline Parameter & $\begin{array}{l}\text { Conc. taken } \\
(\mu \mathrm{g} / \mathrm{mL})\end{array}$ & $\begin{array}{l}\text { Conc. Found } \\
\quad(\mu \mathrm{g} / \mathrm{mL})\end{array}$ & $\%$ recovery & Parameter & $\begin{array}{c}\text { Conc. taken } \\
(\mu \mathrm{g} / \mathrm{mL})\end{array}$ & $\begin{array}{l}\text { Conc. Found } \\
\qquad(\mu \mathrm{g} / \mathrm{mL})\end{array}$ & $\%$ recovery \\
\hline \multirow{5}{*}{ FEB } & 0.05 & 0.0517 & 103.40 & & 0.08 & 0.0787 & 98.38 \\
\hline & 0.1 & 0.0972 & 97.20 & & 0.2 & 0.1992 & 99.60 \\
\hline & 0.15 & 0.1479 & 98.60 & DIC & 0.3 & 0.3082 & 102.73 \\
\hline & 0.2 & 0.2043 & 102.15 & & 0.4 & 0.3916 & 97.90 \\
\hline & 0.3 & 0.2988 & 99.60 & & 0.5 & 0.5023 & 100.46 \\
\hline Mean \% & & & $100.19 \%$ & Mean \% & & & $99.81 \%$ \\
\hline$\pm \mathrm{SD}$ & & & 2.55 & $\pm \mathrm{SD}$ & & & 1.92 \\
\hline$\%$ RSD & & & 2.545 & $\%$ RSD & & & 1.924 \\
\hline
\end{tabular}

\section{Assessment of Greenness of the Proposed Method}

Eco-Scale was proposed and calculated by assessing penalty points obtained by each step during the whole analysis which doesn't match the ideas of greener chemistry. A green analysis is deemed ideal if it has an Eco-Scale value of 100, excellent if $>75$, acceptable if $>50$, and inadequate if $<50$. The penalty points are assigned for high amounts and high hazards connected with utilization of chemicals, high energy consumption, occupational hazards and generation of wastes. The analytical Eco-Scale has advantages compared to other scales due to the simplicity of calculating its score and pointing out to different aspects of the environmental impact of analytical methods in its assessment procedure [27]. The proposed method is superior over the two reported HPLC methods. The analytical Eco-Scale value of the proposed method was calculated and its score was 79 which is very close to be an excellent green analysis than the reported method [9] its score was 62 which is very close to be an acceptable green analysis and the other reported method [10] its score was 71 which is very close to be an acceptable green analysis as shown in Table 8. Additionally; The GAPI [19] utilizes five pentagrams to assess and quantify the environmental influence of every step of an analytical method with a color code; green, yellow and red signifying low, medium and high influence on the environment, respectively. The GAPI tool also keeps in account new criteria as the health and safety. Interpretation of the GAPI pentagrams for the proposed and the reported methods is shown in Figures 5(a)-(c). Revealed that: the proposed UHPLC method has the least environmental impact as 10 fields were shaded green, 4 yellow and only 1 red as shown in Figure 5(a), the reported method [9] showed 6 green, 7 yellow and 2 red fields; Figure 5(b) and the other reported method [10] showed 8 green, 3 yellow and 4 red fields; Figure 5(c), The green evaluation for the proposed method and the reported methods using the GAPI tool indicated the greenness of the suggested method. 


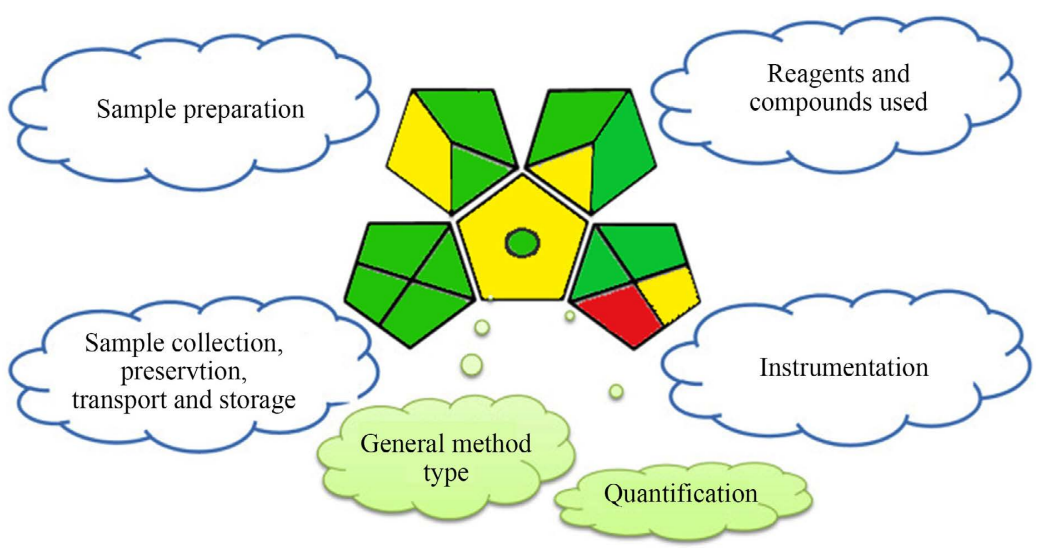

(a)

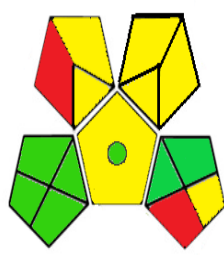

(b)

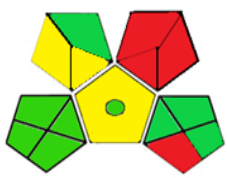

(c)

Figure 5. GAPI assessment of the green profile of the proposed method (a) and reported methods (b and c).

Table 8. The penalty points of the proposed methods\& Reported methods according to the analytical Eco-Scale.

\begin{tabular}{cccc}
\hline Category & $\begin{array}{c}\text { Proposed } \\
\text { method }\end{array}$ & $\begin{array}{c}\text { Reported } \\
\text { method [9] }\end{array}$ & $\begin{array}{c}\text { Reported } \\
\text { method [10] }\end{array}$ \\
\hline Reagents/Instruments & 12 & Penalty points & \\
\hline Methanol & 0 & 12 & 12 \\
Water & & & 2 \\
Phosphate buffer & & & 4 \\
Acetonitrile & & 12 & \\
Sodium hydroxide & 3 & 6 & 1 \\
Formic acid & 1 & 1 & 1 \\
Diethyl ether & 1 & & 2 \\
Ethanol & & 2 & 0 \\
Centrifuge & 0 & 0 & 0 \\
Sonicator & 0 & 5 & 5 \\
HPLC & 5 & 38 & 29 \\
UPLC & 22 & Acceptable & Acceptable \\
\hline Occupational hazard & $22=79$ & $100-38=62$ & $100-29=71$ \\
Waste & Excellent & &
\end{tabular}




\section{Conclusion}

The proposed UHPLC method provides simple, specific, rapid and green quantitative analysis of FEB and DIC in their raw materials, combined tablets and in human plasma. The proposed method is accurate, cheap and rapid enough to be applied in the quality control analysis of both drugs. Satisfactory precision and accuracy, minimum cost, quicker analysis and environmentally safe are the core features of this method.

\section{Funding}

No external funding is included.

\section{Conflicts of Interest}

The authors declare no conflicts of interest regarding the publication of this paper.

\section{References}

[1] Sweetman, S.C. (2011) Martindale: The Complete Drug Reference. 37th Edition, Pharmaceutical Press, London.

[2] Edwards, N.L. (2009) Febuxostat: A New Treatment for Hyperuricaemia in Gout. Rheumatology, 48, ii15-ii19. https://doi.org/10.1093/rheumatology/kep088

[3] Becker, M.A., Schumacher, H.R., Espinoza, L.R., Wells, A.F., MacDonald, P.A., Lioyd, E. and Lademacher, C. (2010) The Urate-Lowering Efficacy and Safety of Febuxostat in the Treatment of the Hyperuricemia of Gout: The CONFIRMS Trial. Arthritis Research and Therapy, 12, Article No. R63. https://doi.org/10.1186/ar2978

[4] Habib, I., Rizk, M., Abou El-Alamin, M.M. and Imam, G.S. (2016) Simultaeous Spectrophotometric Determination of Febuxostat and Diclofenac in Pharmaceutical Dosage Using Chemometrics Methods. European Journal of Biomedical and Pharmaceutical Sciences, 3, 188-195.

[5] Modi, N.R., Mothalia, C.P., Prajapati, K.R., Parmar, R.R., Shah, V.N. and Shah, D. (2013) Development and Validation of Spectrophotometric Method for Simultaneous Estimation of Diclofenac Potassium and Febuxostat in Tablet Dosage Forms. International Journal of Pharmaceutical Sciences, 4, 268-278.

[6] Derasari, J.M. and Patel, V.P (2013) Spectrophotometric Determination of Febuxostat and Diclofenac Potassium in Their Combined Dosage form by Simultaneous Equation and First Order Derivative Methods. Asian Journal of Research in Chemistry, 6, 968-972.

[7] El-Yazbi, F.A, Amin, O.A., El-Kimary, E.I., Khamis, E.F. and Younis, S.E. (2016) HPTLC and Spectrophotometric Estimation of Febuxostat and Diclofenac Potassium in their Combined Tablets. Journal of Chromatographic Science, 54, 1146-1152. https://doi.org/10.1093/chromsci/bmw091

[8] El-Yazbi, F.A, Amin, O.A., El-Kimary, E.I., Khamis, E.F. and Younis, S.E. (2018) High-Performance Thin-Layer Chromatographic Methods for the Determination of Febuxostat and Febuxostat/Diclofenac Combination in Human Plasma. Journal of Chromatography B, 1086, 89-96. https://doi.org/10.1016/j.jchromb.2018.04.020

[9] El-Yazbi, F.A., Amin, O.A., El-Kimary, E.I., Khamis, E.F., Younis, S.E, Elkhatib, M.A. and El-Yazbi, A.F. (2019) A Novel HPLC-DAD Method for Simultaneous De- 
termination of Febuxostat and Diclofenac in Biological Samples: Pharmacokinetic Outcomes. Bioanalysis, 11, 41-54. https://doi.org/10.4155/bio-2018-0219

[10] Vaibhav, S., Mohit, M. and Sadhana, R. (2013) Validation of RP-HPLC for Simultaneous Estimation of Febuxostat and Diclofenac Potassium in Bulk Drug and in BI Layer Tablet Formulation. International Research Journal Pharmacy, 4, 103-106. https://doi.org/10.7897/2230-8407.04921

[11] The British Pharmacopoeia Commission (2016) The British Pharmacopoeia. Her Majesty's Stationery Office, London.

[12] The Directorate for the Quality of Medicines \& Healthcare of the Council of Europe (2014) The European Pharmacopeia. 8th Edition, the Council of Europe, Strasbourg.

[13] United States Pharmacopeial Convention (2011) The United States Pharmacopeia. 33rd Edition, United States Pharmacopeial Convention, Inc., Rockville.

[14] Koel, M. and Kaljurand, M. (2006) Application of the Principles of Green Chemistry in Analytical Chemistry. Pure and Applied Chemistry, 78, 1993-2002. https://doi.org/10.1351/pac200678111993

[15] Tobiszewski, M. (2016) Metrics for Green Analytical Chemistry. Analytical Methods, 8, 2993-2999. https://doi.org/10.1039/C6AY00478D

[16] Korany, M., Mahgoub, H., Haggag, R., Ragab, M. and Elmalla, O. (2017) Green Chemistry: Analytical and Chromatography. Journal of Liquid Chromatography and Related Technologies, 40, 839-852. https://doi.org/10.1080/10826076.2017.1373672

[17] Piontek, J.C., Zalewski, P., Jelinska, A. and Garbacki, P. (2013) UHPLC: The Greening Face of Liquid Chromatography. Chromatographia, 76, 1429-1437.

https://doi.org/10.1007/s10337-013-2434-6

[18] Gałuszka, A., Migaszewski, Z.M., Konieczka, P. and Namiesnik, J. (2012) Analytical Eco-Scale for Assessing the Greenness of Analytical Procedures. Trends in Analytical Chemistry, 37, 61-72. https://doi.org/10.1016/j.trac.2012.03.013

[19] Płotka-Wasylka, J. (2018) A New Tool for the Evaluation of the Analytical Procedure: Green Analytical Procedure Index. Talanta, 181, 204-209. https://doi.org/10.1016/j.talanta.2018.01.013

[20] Sheldon, R.A. (2012) Fundamentals of Green Chemistry: Efficiency in Reaction Design. Chemical Society Reviews, 41, 1437-1451. https://doi.org/10.1039/C1CS15219J

[21] Prat, D., Hayler, J. and Wells, A. (2014) A Survey of Solvent Selection Guide. Green Chemistry, 16, 4546-4551. https://doi.org/10.1039/C4GC01149J

[22] Mohamed, H.M. (2015) Green, Environment-Friendly, Analytical Tools Give Insights in Pharmaceuticals and Cosmetics Analysis. Trends in Analytical Chemistry, 66, 176-192. https://doi.org/10.1016/j.trac.2014.11.010

[23] International Conference on Harmonization (ICH) (2005) Technical Requirements for the Registration of Pharmaceutical for Human Use, of Analytical Procedures: Text and Methodology Q2 (R1). Geneva.

[24] Miller, J.C. and Miller, J.N. (2005) Statistics and Chemometrics for Analytical Chemistry. 5th Edition, Pearson Education Limited, Harlow.

[25] Zhang, M., Di, X., Xu, L., Xu, J., Yang, Y., Jiang, N., Song, L. and Xu, X. (2014) Pharmacokinetics and Pharmacodynamics of Febuxostat under Fasting Conditions in Healthy Individuals. Experimental and Therapeutic Medicine, 7, 393-396. https://doi.org/10.3892/etm.2013.1414

[26] Riess, W., Stierlin, H., Degen, P., Faigle, J.W., Gerardin, A. and Moppert, J. (2009) Pharmacokinetics and Metabolism of the Anti-Inflammatory Agent Voltaren. Scandinavian Journal of Rheumatology, 7, 17-29. 
https://doi.org/10.3109/03009747809097212

[27] Tobiszewski, M., Marc, M., Galuszka, A. and Namiesnik, J. (2015) Green Chemistry Metrics with Special Reference to Green Analytical Chemistry. Molecules, 20, 10928-10946. https://doi.org/10.3390/molecules200610928 